\title{
Rapid Detection of Methicillin-Resistant Staphylococcus aureus Directly from Blood for the Diagnosis of Bloodstream Infections: A Mini-Review
}

\author{
Anna Rita Buonomini ${ }^{1}$, Elisabetta Riva ${ }^{1}$, Giovanni Di Bonaventura ${ }^{2,3}{ }^{-1}$ and \\ Giovanni Gherardi ${ }^{1, *}$ \\ 1 Department of Medicine, Campus Biomedico University, Via Alvaro del Portillo 200, 00128 Rome, Italy; \\ a.buonomini@unicampus.it (A.R.B.); e.riva@unicampus.it (E.R.) \\ 2 Department of Medical, Oral and Biotechnological Sciences, G. d'Annunzio" University of Chieti-Pescara, \\ Via Vestini 31, 66100 Chieti, Italy; g.dibonaventura@unich.it \\ 3 Center for Advanced Studies and Technology (CAST), "G. d'Annunzio” University of Chieti-Pescara, \\ Via Luigi Polacchi 11, 66100 Chieti, Italy \\ * Correspondence: g.gherardi@unicampus.it
}

Received: 13 August 2020; Accepted: 14 October 2020; Published: 15 October 2020

\begin{abstract}
Staphylococcus aureus represents a major human pathogen able to cause a number of infections, especially bloodstream infections (BSI). Clinical use of methicillin has led to the emergence of methicillin-resistant S. aureus (MRSA) and MRSA-BSI have been reported to be associated with high morbidity and mortality. Clinical diagnosis of BSI is based on the results from blood culture that, although considered the gold standard method, is time-consuming. For this reason, rapid diagnostic tests to identify the presence of methicillin-susceptible S. aureus (MSSA) and MRSA isolates directly in blood cultures are being used with increasing frequency to rapidly commence targeted antimicrobial therapy, also in the light of antimicrobial stewardship efforts. Here, we review and report the most common rapid non-molecular and molecular methods currently available to detect the presence of MRSA directly from blood.
\end{abstract}

Keywords: Staphylococcus aureus; methicillin resistance; bloodstream infections; rapid tests

\section{Introduction}

Staphylococcus aureus, a Gram-positive coagulase-positive pathogen belonging to the family Staphylococcaceae, usually acts as a commensal of the human microbiota but it can also become an opportunistic pathogen due to the ability to adapt to different host and environmental conditions and to cause many infections [1-4]. It can cause skin, soft tissue, and lower respiratory tract infections, as well as those related to medical instrumentation, and some serious deep-seated infections such as osteomyelitis and endocarditis. Indeed, S. aureus continue to be leading cause of bloodstream infections (BSI) [5].

A major clinical concern for $S$. aureus is its ability to acquire antibiotic resistance, particularly methicillin resistance consequent to methicillin usage, and methicillin-resistant S. aureus (MRSA) has been associated with high morbidity and mortality rates [6-8]. MRSA strains carry an altered penicillin-binding protein (PBP 2a or PBP 2') with decreased binding affinity for penicillin encoded by the gene mec $A$ carried on a mobile genetic element, the staphylococcal cassette chromosome mec (SCCmec) [9-13]. A novel mecA homologue determinant, named mecC, has been rarely identified among MRSA [14]. MRSA isolates are, therefore, resistant to most available beta-lactam drugs, whilst they remain susceptible to the new cephalosporins ceftaroline and ceftobiprole. 
S. aureus BSI are associated with a 30-day mortality up to $46 \%$ [15-17]. Earlier appropriation of antibiotics has been associated with reduced mortality in the setting of BSI, including S. aureus bacteremia [18-21]. Clinical diagnosis of BSI depends on traditional blood culture results, although bacterial identification by these conventional methods is time-consuming. Molecular diagnostic tests to identify the presence of methicillin-susceptible S. aureus (MSSA) and MRSA isolates directly in critical clinical specimens, such as blood cultures, are being used, providing results in $1-5 \mathrm{~h}$ without the requirement for bacterial growth onto agar media, with increasing frequency in guiding antimicrobial therapy for staphylococcal infections as part of antimicrobial stewardship programs [22-27]. In recent years, several molecular panels able to simultaneously detect many organisms, including MSSA/MRSA, in one sample have been developed for the diagnosis of infectious syndromes. Depending on the test used, MRSA can be detected 12-48 h earlier than with traditional methodologies [28-30].

In this paper, we provide an overview of the most commonly reported non-molecular and molecular rapid methods currently available to detect the presence of $S$. aureus and MRSA directly from blood. Table 1 summarizes the commercially available blood culture-independent and -dependent methods. 
Table 1. Commercially available blood culture-independent and-dependent methods for rapid detection of S. aureus and MRSA for the diagnosis of bloodstream infection.

\begin{tabular}{|c|c|c|c|}
\hline System (Manufacturer) & Principle & Time to Result (Hours) & Methicillin Resistance Detection $^{a}$ \\
\hline \multicolumn{4}{|c|}{ Blood Culture-Independent Methods } \\
\hline Septifast (Roche Molecular Diagnostics) & Multiplex real-time PCR & $4-6$ & yes \\
\hline MagicPlex (Seegene) & Multiplex real-time PCR & $3-5$ & yes \\
\hline SepsiTest (Molzym) & Broad range PCR + sequencing & $8-12$ & no \\
\hline VYOO (Analytic Jena) & Multiplex PCR + gel electrophoresis & $7-8$ & yes \\
\hline PLEX-ID Iridica (Abbott Molecular) & Multiplex PCR + ESI-MS & $6-8$ & yes \\
\hline T2Dx bacteria panel (T2 Biosystems) & PCR + magnetic resonance technology & 6 & no \\
\hline \multicolumn{4}{|c|}{ Blood Culture-Dependent Methods } \\
\hline Microflex (Bruker Daltonics) & MALDI-TOF & $0.2-0.5$ & no \\
\hline Vitek MS (bioMérieux) & MALDI-TOF & $0.2-0.5$ & no \\
\hline S. aureus/CNS PNA-FISH/Quick-FISH (AdvanDx) & FISH with PNA probes & $0.5-3$ & no \\
\hline Verigene Gram-positive blood culture (BC-GP) assay (Luminex) & Multiplex PCR + solid-microarray detection & 2.5 & yes \\
\hline Prove-it Sepsis (Mobidiag) & Broad range PCR + microarray & 3.5 & yes \\
\hline GeneXpert MRSA/SA BC Assay (Cepheid) & Multiplex real-time PCR & 1 & yes \\
\hline BD Max StaphSR assay (BD) & Multiplex real-time PCR & 1.5 & yes \\
\hline FilmArray BCID panel (BioFire; bioMérieux) & FilmArray BCID panel & 1 & yes \\
\hline Eazyplex MRSA (Amplex BioSystems) & Loop-mediated isothermal amplification & 0.5 & yes \\
\hline Accelerate Pheno System (Accelerate Diagnostics) & FISH (ID) + morpho-kinetic cellular analysis (AST) & 1.5 (ID)7 (AST) & yes \\
\hline Direct Tube Coagulase Test & Clot formation by rabbit plasma & $2-24$ & no \\
\hline BinaxNOW Staphylococcus aureus (BNSA) (Alere) & Immunochromatographic test & 0.5 & no \\
\hline
\end{tabular}

${ }^{a}$ Based on genotype (presence of $m e c A$; presence both of $m e c A$ and $m e c C$ ) or phenotype analysis. 


\section{Molecular Blood Culture-Independent Methods for Identification Directly from Blood Samples}

In these methods (Table 1), the identification of S. aureus directly from blood samples can take place during or after nucleic acid amplification by multiplex real-time PCR [31,32]. The automated system LightCycler SeptiFast (Roche Molecular System, Basel, Switzerland) is able to identify 19 pathogens including S. aureus and mecA, and in the multistep automated system MagicPlex Sepsis Test (Seegene, Seoul, Korea) conventional and real-time PCR are associated to detect several pathogens included S. aureus and some resistance genes including mecA [31]. Identification systems directly from blood samples after amplification are carried out in the SepsiTest (Molzym, Bremen, Germany), a semiautomated system based on broad-range PCRs using universal primers, followed by sequencing by BLAST with a time to result ranging between 8 and $12 \mathrm{~h}$; the VYOO system (SIRS-Lab, Jena, Germany) DNA amplification method based on multiple PCRs that target the 16S rRNA gene followed by an electrophoresis on an agarose gel with a time to results of about $8 \mathrm{~h}$; and the PLEX-ID Iridica (Abbott Molecular, Abbott Park, IL, USA), a universal molecular device that can detect and identify up to 800 pathogens, including S. aureus, coupling microbe detection by PCR and amplicon analysis by electrospray/ionization mass spectrometry (ESI-MS) with a time to result of about $6-8 \mathrm{~h}[31,33]$. Recently, the automated T2Dx instrument platform (T2 Biosystems, Lexington, MD, USA) has been developed using T2 magnetic resonance (T2MR) technology to provide a 'sample-to-result' clinical diagnostic test with final results obtained by $6 \mathrm{~h}$. This enables multiplex detection of ESKAPEc (Enterococcus faecium, S. aureus, Klebsiella pneumoniae, Acinetobacter baumannii, Pseudomonas aeruginosa, Escherichia coli) pathogens in a single whole-blood sample, achieving overall sensitivity and specificity rates of 90 and $98 \%$, respectively [34,35].

\section{Positive Blood Culture-Dependent Methods for Identification and Antimicrobial Susceptibility Testing of S. aureus}

Blood culture-dependent methods for diagnosis of S. aureus BSI can be divided into systems applied to different protocols: (i) directly from positive blood culture bottles; (ii) directly from positive blood cultures from pellets; and (iii) from early subcultures after a short incubation period of approximately 3-4 h [32]. For the latter two protocols that use pellets and early subcultures, identification and antimicrobial susceptibility testing require a pure subculture, and MALDI-TOF MS, currently considered the best method for rapid bacterial identification, with the two most common platforms represented by Microflex (Bruker Daltonics, Billerica, MD, USA) and Vitek MS (bioMérieux, Marcy l'Etoile, France), is used for bacterial identification [36-39]. Identification using MALDI-TOF MS is based on the comparison of surface and ribosomal protein profiles obtained by mass spectrometry with a database of protein profiles of well characterized bacterial species [38].

For the protocol applied directly to positive blood culture bottles, the major molecular methods are fluorescence in situ hybridization (FISH), microarrays and some rapid PCR-based tests [38]. FISH is a fluorescence microscopy method based on the specific binding of fluorescent nucleic acid probes on complementary bacterial $16 \mathrm{~S}$ rRNA sequences. The panel available for staphylococci is the S. aureus/coagulase-negative [38]. The commercial solutions PNA-FISH and Quick-FISH (AdvanDx, Woburn, MA, USA) display a time to result of about 1.5 to $3 \mathrm{~h}$ [38]. Recently, a rapid and direct detection of $S$. aureus in 41 positive blood cultures through three molecular beacon-based probes by fluorescence in situ hybridization (MB-FISH) has been described, with specificity and sensitivity of $100 \%$ and $93.75 \%$, respectively [40].

Microarrays generally contain probes for the detection of the most common pathogens along with resistance genes. The Verigene system (Nanosphere, Northbrook, IL, USA) comprises distinct kits for Gram-negative and Gram-positive bacteria and allows the detection of 12 Gram-positive included S. aureus $[41,42]$. In a study evaluating the performance of the Verigene Gram-positive blood culture assay (BC-GP, Luminex Corporation, Austin, TX, USA), all MRSA tested were correctly identified [43]. The Prove-it Sepsis assay (Mobidiag, Esbo, Finland) is another molecular microarray which combines broad-range PCR and microarray-based assay with a turnaround time of $3.5 \mathrm{~h} \mathrm{[44].}$ 
Rapid multiplex real-time PCR assays that allow both detection and identification of MSSA and MRSA have been developed for blood cultures, such as GeneXpert MRSA/SA BC Assay (Cepheid, Sunnyvale, CA, USA), and the BD Max StaphSR assay (Becton Dickinson GeneOhm, San Diego, CA, USA), with results available in approximately $1.5 \mathrm{~h}$ [45-48]. The GeneXpert MRSA/SA BC 2013 test detects three targets: the gene encoding staphylococcal protein A (spa), mecA, and the junction region between orfX chromosome and the SCCmec element. In the updated version, rule-based algorithms allow differentiation between MSSA and MRSA; further, it has successfully detected both spa and SCCmec variants of MRSA, although genetic variations that may interfere with Xpert MRSA/SA BC test results have been observed, if rarely [49]. The BD Max StaphSR assay is an automated qualitative in vitro diagnostic test using a simplified molecular platform with minimal hands-on time; it requires minimal technical skill with results available within $2 \mathrm{~h}$ of the blood culture signaling positive, with excellent sensitivity (MRSA: 100\%; MSSA: 99.1\%) and a specificity of $100 \%$ [50]. A comparison of the next-generation Xpert MRSA/SA BC test and the GeneOhm StaphSR assay for identification of MSSA/MRSA in positive blood cultures reported a sensitivity of $99.2 \%$ and a specificity of $96.5 \%$ for identifying S. aureus, as well as a sensitivity of $94.3 \%$ and a specificity of $97.8 \%$ for identifying MRSA [51].

Among PCR-based methods, the FilmArray BCID panel (Idaho Technology, Salt Lake City, UT, USA) also needs to be mentioned due to its common use. It is a multiplex PCR-based system designed to detect in positive blood cultures the most prevalent pathogens and resistance genes, including S. aureus and mecA [52]. Moreover, loop-mediated isothermal amplification (LAMP), an amplification technique that uses Bst DNA polymerase with strand displacing activity, has also been introduced to rapidly identify the most common pathogens and their major resistance genes from positive blood culture bottles within a time frame of $30 \mathrm{~min}$ [53-55]. Among three different eazyplex ${ }^{\circledR}$ LAMP assays available, the eazyplex ${ }^{\circledR}$ MRSA (Amplex BioSystems, Giessen, Germany) is a CE-labeled commercial test for the detection of S. aureus, S. epidermidis, mecA, and mecC from nasal and pharyngeal swabs, but it has also been used with a preliminary blood culture protocol, with sensitivity and specificity of almost $100 \%$ [56]. A novel and unique approach is the Accelerate Pheno system (Accelerate Diagnostics, Tucson, AZ, USA) that allows identification of several bacteria included S. aureus and fungi by FISH, as well as phenotypic antimicrobial susceptibility testing by morpho-kinetic cellular analysis directly from positive blood culture [57].

A few rapid non-molecular methods have also been developed for rapid identification of MRSA from blood culture. The Direct Tube Coagulase Test has been described as a rapid, simple, and inexpensive method [58]. After confirmation by Gram staining, clot formation is assessed after incubation of a mixture of drops of culture broth and $0.5 \mathrm{~mL}$ of rabbit plasma at $35^{\circ} \mathrm{C}$ for 2 and $4 \mathrm{~h}$, with sensitivity and specificity of about $80 \%$ and $100 \%$, respectively [58,59]. Indeed, the rapid BinaxNOW Staphylococcus aureus (BNSA) immunochromatographic test (Alere Scarborough, Inc., Scarborough, ME, USA) was found to accurately differentiate $S$. aureus from coagulase-negative staphylococci (CoNS) and other Gram-positive cocci directly from blood culture bottles, within $30 \mathrm{~min}$ from the time of blood culture positivity with sensitivity and specificity of $95.8 \%$ and $99.6 \%$, respectively [60].

\section{Other Rapid Antimicrobial Susceptibility Testing (AST) Phenotypic Methods Directly on Positive Blood Cultures}

For rapid AST, besides the methods cited above, other phenotypic approaches have been described with or without a subculture step (Table 2). They can be performed directly from positive blood culture bottles, by bacterial pellet or after an early incubation protocol. The Accelerate Pheno system has been previously cited and allows phenotypic antimicrobial susceptibility testing by morpho-kinetic cellular analysis with time to result of approximately $7 \mathrm{~h}$. Other rapid AST phenotypic methods include the automated broth microdilution method by Phoenix and Vitek, disk diffusion methods, and gradient strips using Etest (bioMérieux) or MIC Strip (Liofilchem) [61-63]. Rapid AST can be also performed directly on blood culture samples tested on Mueller-Hinton Rapid agar (MHR-SIR) with a 
time delay of 6-8 $\mathrm{h}$ associated with a significant time saving $(17 \mathrm{~h})$, according to the appropriateness of the antibiotic prescription $[64,65]$. AST by Alfred AST system performed directly from positive blood bottles has also been recently reported. This system, based on the detection of growth by turbidimetry through a technology based on light scattering, is considered a valid and fast method to obtain antimicrobial susceptibility results within the same work shift after blood culture positivity [66]. Semi-quantitative MALDI-TOF for growth rate analysis has been described as a useful method to provide a resistance profile independent of resistance mechanism for antimicrobial susceptibility testing in S. aureus, yielding an overall accuracy rate of $95 \%$, including oxacillin susceptibility testing [67]. It is also worthwhile to mention specific protocols that offer a significant benefit to early detection of MRSA in positive blood cultures. For example, the blood culture-dependent three-hour short incubation protocol combines MALDI TOF identification with the qualitative immunochromatographic PBP2a detection test assay (Alere) to detect methicillin resistance, yielding a sensitivity and specificity of $87.5 \%$ and $100 \%$, respectively $[68,69]$. Recently, a revised version of an immunochromatographic assay for detection of $m e c A$ - and $m e c C$-positive MRSA has been described [70].

Table 2. Rapid antimicrobial susceptibility testing phenotypic methods to detect S. aureus methicillin resistance directly from positive blood cultures, bacterial pellet or early (3-4 h of incubation) subculture.

\begin{tabular}{ccc}
\hline System (Manufacturer) & Principle & Time to Result (Hours) \\
\hline Accelerate Pheno System (Accelerate Diagnostics) & Morpho-kinetic cellular analysis & 7 \\
Phoenix (BD) & Broth microdilution & 7 \\
Vitek (bioMérieux) & Broth microdilution & 7 \\
Several systems/manufacturers a & Disk diffusion methods & $16-24$ \\
Etest (bioMérieux), MIC Strip (Liofilchem) & Gradient strips & $16-24$ \\
Alfred AST system (Alifax) & Turbidimetry & 5 \\
Microflex (Bruker Daltonics) & Mass spectrometry-based tests & $3-4$ \\
PBP2a detection test assay (Alere) & Immunochromatographic test & $<1$ \\
\hline
\end{tabular}

a Several manufacturers can produce antimicrobial disks for disk diffusion method.

\section{Conclusions}

In this mini-review, we have reported and discussed the main rapid methods currently available to detect the presence of MSSA/MRSA directly from blood. The major limitation of this paper is due to the difficulty in making a systematic review from the literature due to the scarce reports that could be retrieved among the published papers using specific and targeted keywords. Therefore, some previously published reviews have been retrieved that describe rapid diagnostic methods not specifically used for MRSA bacteremia but applied to all possible pathogens causing BSI.

Multidrug-resistant Gram-negative bacteria, such as carbapenem-resistant P. aeruginosa and A. baumannii, as well as carbapenem-resistant and extended spectrum beta lactamases-producing Enterobacterales, represent the highest priority of resistant pathogens for which new antibiotics are urgently needed, as indicated by the World Health Organization [71]. Treating severe infections due to multidrug-resistant Gram-negative bacteria is one of the most important challenges for clinicians worldwide and the major efforts of the scientific community have been mainly focused on the development of rapid microbiological tests for BSI due to multidrug resistant Gram-negative bacteria [72]. However, it has been reported that in routine patient care S. aureus is the most common pathogen isolated from blood and, together with Enterobacterales, accounts for approximately half of all blood culture isolates in most studies [30]. Optimal patient care requires access to necessary laboratory testing including clinical microbiology, and a rethinking of hours of operation is required, i.e., $24 \mathrm{~h} / 7$ days a week open laboratory, to shorten time of accurate result reporting [73]. Rapid identification and differentiation of $S$. aureus from CoNS in blood culture bottles is reported to have a major impact on improving patient outcomes, decreasing length of hospital stays, and reducing health care expenses $[23,74,75]$. Inappropriate antibiotic therapy in cases of $S$. aureus BSI has been found to be associated with a higher risk of mortality and extended hospital length of stays, therefore appropriate 
antimicrobial therapy seems to be the most important factor associated with a better clinical outcome. Even though MRSA epidemiology varies between countries, MRSA risk factors can be easily identifiable, such as previous MRSA infection or colonization, coming from long-term care facility, and chronic renal diseases [76]. The risk factors should be also considered before expensive rapid diagnostic tests are performed. Conventional identification of $S$. aureus from blood cultures requires isolated colonies and generally takes 18 to $24 \mathrm{~h}$ after positive signaling on continuously monitored, automated blood culture systems. Rapid non-molecular and molecular methods are currently available to detect the presence of MRSA directly from clinical specimens [29,77]. Today, new technologies are available to rapidly obtain bacterial identification and antibiotic susceptibility results, maintaining high efficiency and sensitivity. Rapid diagnostic procedure represents one of the essential actions needed to improve BSI diagnosis [78]. Rapid detection of MRSA in cases of bacteremia and early notification of results in conjunction with an antimicrobial stewardship program can potentially reduce unnecessary antimicrobial costs and improve care.

Author Contributions: Conception and methodology of the work, writing—review \& editing, A.R.B., E.R., G.D.B., G.G. All authors have read and agreed to the published version of the manuscript.

Funding: This research received no external funding

Conflicts of Interest: The authors declare no conflict of interest.

\section{References}

1. Diekema, D.J.; Pfaller, M.A.; Schmitz, F.J; Smayevsky, J.; Bell, J.; Jones, R.N.; Beach, M.; SENTRY Partcipants Group. Survey of infections due to Staphylococcus species: Frequency of occurrence and antimicrobial susceptibility of isolates collected in the United States, Canada, Latin America, Europe, and the Western Pacific region for the SENTRY Antimicrobial Surveillance Program, 1997-1999. Clin. Infect. Dis. 2001, 32, S114-S132. [PubMed]

2. Lakhundi, S.; Zhang, K. Methicillin-resistant Staphylococcus aureus: Molecular characterization, evolution, and epidemiology. Clin. Microbiol. Rev. 2018, 31, e00020-Ce18. [CrossRef] [PubMed]

3. Lowy, F.D. Staphylococcus aureus infections. N. Engl. J. Med. 1998, 339, 520-532. [CrossRef]

4. Wertheim, H.F.; Melles, D.C.; Vos, M.C.; van Leeuwen, W.; van Belkum, A.; Verbrugh, H.A.; Nouwen, J.L. The role of nasal carriage in Staphylococcus aureus infections. Lancet Infect. Dis. 2005, 5, 751-762. [CrossRef]

5. Kourtis, A.P.; Hatfield, K.; Baggs, J.; Mu, Y.; See, I.; Epson, E.; Nadle, J.; Kainer, M.A.; Dumyati, G.; Petit, S. Vital signs: Epidemiology and recent trends in methicillin-resistant and in methicillin-susceptible Staphylococcus aureus bloodstream infections-United States. MMWR Morb. Mortal. Wkly Rep. 2019, 68, 214-219. [CrossRef] [PubMed]

6. Thampi, N.; Showler, A.; Burry, L.; Bai, A.D.; Steinberg, M.; Ricciuto, D.R.; Bell, C.M.; Morris, A.M. Multicenter study of health care cost of patients admitted to hospital with Staphylococcus aureus bacteremia: Impact of length of stay and intensity of care. Am. J. Infect. Control. 2015, 43, 739-744. [CrossRef]

7. Whitby, M.; McLaws, M.L.; Berry, G. Risk of death from methicillin-resistant Staphylococcus aureus bacteraemia: A meta-analysis. Med. J. Aust. 2001, 175, 264-267. [CrossRef]

8. Wolk, D.M.; Struelens, M.J.; Pancholi, P.; Davis, T.; Della-Latta, P.; Fuller, D.; Picton, E.; Dickenson, R.; Denis, O.; Johnson, D.; et al. Rapid detection of Staphylococcus aureus and methicillin-resistant S. aureus (MRSA) in wound specimens and blood cultures: Multicenter preclinical evaluation of the Cepheid Xpert MRSA/SA skin and soft tissue and blood culture assays. J. Clin. Microbiol. 2009, 47, 823-826. [CrossRef]

9. Hartman, B.J.; Tomasz, A. Low-affinity penicillin-binding protein associated with beta lactam resistance in Staphylococcus aureus. J. Bacteriol. 1984, 158, 513-516. [CrossRef] [PubMed]

10. Hiramatsu, K.; Asada, K.; Suzuki, E.; Okonogi, K.; Yokota, T. Molecular cloning and nucleotide sequence determination of the regulator region of mecA gene in methicillin-resistant Staphylococcus aureus (MRSA). FEBS Lett. 1992, 298, 133-136. [CrossRef]

11. Katayama, Y.; Ito, T.; Hiramatsu, K. A new class of genetic element, staphylococcus cassette chromosome mec, encodes methicillin resistance in Staphylococcus aureus. Antimicrob. Agents Chemother. 2000, 44, 1549-1555. [CrossRef] 
12. Matsuhashi, M.; Song, M.D.; Ishino, F.; Wachi, M.; Doi, M.; Inoue, M.; Ubukata, K.; Yamashita, N.; Konno, M. Molecular cloning of the gene of a penicillin-binding protein supposed to cause high resistance to betalactam antibiotics in Staphylococcus aureus. J. Bacteriol. 1986, 167, 975-980. [CrossRef] [PubMed]

13. Utsui, Y.; Yokota, T. Role of an altered penicillin-binding protein in methicillin- and cephem-resistant Staphylococcus aureus. Antimicrob. Agents Chemother. 1985, 28, 397-403. [CrossRef]

14. García-Álvarez, L.; Holden, M.T.; Lindsay, H.; Webb, C.R.; Brown, D.F.; Curran, M.D.; Walpole, E.; Brooks, K.; Pickard, D.J.; Teale, C.; et al. Methicillin-resistant Staphylococcus aureus with a novel mecA homologue in human and bovine populations in the UK and Denmark: A descriptive study. Lancet Infect. Dis. 2011, 11, 595-603. [CrossRef]

15. Eby, J.C.; Richey, M.M.; Platts-Mills, J.A.; Mathers, A.J.; Novicoff, W.M.; Cox, H.L. A healthcare improvement intervention combining nucleic acid microarray testing with direct physician response for management of Staphylococcus aureus bacteremia. Clin. Infect. Dis. 2018, 66, 64-71. [CrossRef]

16. Robinson, J.O.; Pozzi-Langhi, S.; Phillips, M.; Pearson, J.C.; Christiansen, K.J.; Coombs, G.W.; Murray, R.J. Formal infectious diseases consultation is associated with decreased mortality in Staphylococcus aureus bacteraemia. Eur. J. Clin. Microbiol. Infect. Dis. 2012, 31, 2421-2428. [CrossRef]

17. Tissot, F.; Calandra, T.; Prod'hom, G.; Taffe, P.; Zanetti, G.; Greub, G.; Senn, L. Mandatory infectious diseases consultation for MRSA bacteremia is associated with reduced mortality. J. Infect. 2014, 69, 226-234. [CrossRef]

18. Gaieski, D.F.; Mikkelsen, M.E.; Band, R.A.; Pines, J.M.; Massone, R.; Furia, F.F.; Shofer, S.F.; Goyal, M. Impact of time to antibiotics on survival in patients with severe sepsis or septic shock in whom early goal-directed therapy was initiated in the emergency department. Crit. Care Med. 2010, 38, 1045-1053. [CrossRef]

19. Lodise, T.P.; McKinnon, P.S.; Swiderski, L.; Rybak, M.J. Outcomes analysis of delayed antibiotic treatment for hospital-acquired Staphylococcus aureus bacteremia. Clin. Infect. Dis. 2003, 36, 1418-1423. [CrossRef]

20. Marchaim, D.; Kaye, K.S.; Fowler, V.G.; Anderson, D.J.; Chawla, V.; Golan, Y.; Karchmer, A.W.; Carmeli, Y. Case-control study to identify factors associated with mortality among patients with methicillin-resistant Staphylococcus aureus bacteraemia. Clin. Microbiol. Infect. 2010, 16, 47-52. [CrossRef]

21. van Hal, S.J.; Jensen, S.O.; Vaska, V.L.; Espedido, B.A.; Paterson, D.L.; Gosbell, I.B. Predictors of mortality in Staphylococcus aureus bacteremia. Clin. Microbiol. Rev. 2012, 25, 362-386. [CrossRef]

22. Banerjee, R.; Teng, C.B.; Cunningham, S.A.; Ihde, S.M.; Steckelberg, J.M.; Moriarty, J.P.; Shah, N.D.; Mandrekar, J.N.; Patel, R. Randomized trial of rapid multiplex polymerase chain reaction-based blood culture identification and susceptibility testing. Clin. Infect. Dis. 2015, 61, 1071-1080. [CrossRef] [PubMed]

23. Bauer, K.A.; West, J.E.; Balada-Llasat, J.M.; Pancholi, P.; Stevenson, K.B.; Goff, D.A. An antimicrobial stewardship program's impact with rapid polymerase chain reaction methicillin-resistant Staphylococcus aureus/S. aureus blood culture test in patients with S. aureus bacteremia. Clin. Infect. Dis. 2010, 51, 1074-1080. [CrossRef]

24. May, L.S.; Rothman, R.E.; Miller, L.G.; Brooks, G.; Zocchi, M.; Zatorski, C.; Dugas, A.F.; Ware, C.E.; Jordan, J.A. A randomized clinical trial comparing use of rapid molecular testing for Staphylococcus aureus for patients with cutaneous abscesses in the emergency department with standard of care. Infect. Control. Hosp. Epidemiol. 2015, 36, 1423-1430. [CrossRef]

25. Messacar, K.; Parker, S.K.; Todd, J.K.; Dominguez, S.R. Implementation of rapid molecular infectious disease diagnostics: The role of diagnostic and antimicrobial stewardship. J. Clin. Microbiol. 2017, 55, 715-723. [CrossRef]

26. Peker, N.; Couto, N.; Sinha, B.; Rossen, J.W. Diagnosis of bloodstream infections from positive blood cultures and directly from blood samples: Recent developments in molecular approaches. Clin. Microbiol. Infect. 2018, 24, 944-955. [CrossRef]

27. Timbrook, T.T.; Morton, J.B.; McConeghy, K.W.; Caffrey, A.R.; Mylonakis, E.; LaPlante, K.L. The effect of molecular rapid diagnostic testing on clinical outcomes in bloodstream infections: A systematic review and meta-analysis. Clin. Infect. Dis. 2017, 64, 15-23. [CrossRef]

28. Mizusawa, M.; Carroll, K.C. Novel strategies for rapid identification and susceptibility testing of MRSA. Expert. Rev. Anti Infect. Ther. 2020, 13, 1-19. [CrossRef]

29. Palavecino, E.L. Rapid methods for detection of MRSA in clinical specimens. Meth. Mol. Biol. 2020, 2069, $29-45$.

30. Wilson, M.L. Development of new methods for detecting bloodstream pathogens. Clin. Microbiol. Infect. 2020, 26, 319-324. [CrossRef] 
31. Opota, O.; Jaton, K.; Greub, G. Microbial diagnosis of bloodstream infection: Towards molecular diagnosis directly from blood. Clin. Microbiol. Infect. 2015, 21, 323-331. [CrossRef] [PubMed]

32. Rello, J.; van Engelen, T.S.R.; Alp, E.; Calandra, T.; Cattoir, V.; Kern, W.V.; Netea, M.G.; Nseir, S.; Opal, S.M.; van de Veerdonk, F.L.; et al. Towards precision medicine in sepsis: A position paper from the European Society of Clinical Microbiology and Infectious Diseases. Clin. Microbiol. Infect. 2018, 24, 1264-1272. [CrossRef] [PubMed]

33. Jordana-Lluch, E.; Giménez, M.; Quesada, M.D.; Rivaya, B.; Marcó, C.; Domínguez, M.J.; Arméstar, F.; Martró, E.; Ausina, V. Evaluation of the broad-range PCR/ESI-MS technology in blood specimens for the molecular diagnosis of bloodstream infections. PLOS ONE 2015, 10, e0140865. [CrossRef] [PubMed]

34. Clancy, C.J.; Hong Nguyen, M. T2 magnetic resonance for the diagnosis of bloodstream infections: Charting a path forward. J. Antimicrob. Chemother. 2018, 73, iv2-iv5. [CrossRef] [PubMed]

35. De Angelis, G.; Posteraro, B.; De Carolis, E.; Menchinelli, G.; Franceschi, F.; Tumbarello, M.; De Pascale, G.; Spanu, T.; Sanguinetti, M. T2Bacteria magnetic resonance assay for the rapid detection of ESKAPEc pathogens directly in whole blood. J. Antimicrob. Chemother. 2018, 73, iv20-iv26. [CrossRef] [PubMed]

36. Idelevich, E.A.; Becker, K. Identification and susceptibility testing from shortly incubated cultures accelerate blood culture diagnostics at no cost. Clin. Infect. Dis. 2016, 62, 268-269. [CrossRef]

37. Idelevich, E.A.; Schule, I.; Grunastel, B.; Wullenweber, J.; Peters, G.; Becker, K. Rapid identification of microorganisms from positive blood cultures by MALDI-TOF mass spectrometry subsequent to very short-term incubation on solid medium. Clin. Microbiol. Infect. 2014, 20, 1001-1006. [CrossRef]

38. Opota, O.; Croxatto, A.; Prod'hom, G.; Greub, G. Blood culture-based diagnosis of bacteraemia: State of the art. Clin. Microbiol. Infect. 2015, 21, 313-322. [CrossRef]

39. Verroken, A.; Defourny, L.; Lechgar, L.; Magnette, A.; Delmee, M.; Glupczynski, Y. Reducing time to identification of positive blood cultures with MALDI-TOF MS analysis after a 5-h subculture. Eur. J. Clin. Microbiol. Infect. Dis. 2015, 34, 405-413. [CrossRef]

40. Zhang, B.; Maimaiti, Y.; Liu, C.; Li, J.; Wang, H.; Lin, H.; Deng, Z.; Lu, X.; Zhang, X. Direct detection of Staphylococcus aureus in positive blood cultures through molecular beacon-based fluorescence in situ hybridization. J. Microbiol. Methods 2019, 159, 34-41. [CrossRef]

41. Mancini, N.; Infurnari, L.; Ghidoli, N.; Valzano, G.; Clementi, N.; Burioni, R.; Clementi, M. Potential impact of a microarray-based nucleic acid assay for rapid detection of Gram-negative bacteria and resistance markers in positive blood cultures. J. Clin. Microbiol. 2014, 52, 1242-1245. [CrossRef] [PubMed]

42. Wojewoda, C.M.; Sercia, L.; Navas, M.; Tuhoy, M.; Wilson, D.; Hall, G.S.; Procop, G.W.; Richter, S.S. Evaluation of the Verigene Gram-positive blood culture nucleic acid test for rapid detection of bacteria and resistance determinants. J. Clin. Microbiol. 2013, 51, 2072-2076. [CrossRef] [PubMed]

43. Aitken, S.L.; Hemmige, V.S.; Koo, H.L.; Vuong, N.N.; Lasco, T.M.; Garey, K.W. Real-world performance of a microarray-based rapid diagnostic for Gram-positive bloodstream infections and potential utility for antimicrobial stewardship. Diagn. Microbiol. Infect. Dis. 2015, 81, 4-8. [CrossRef]

44. Tissari, P.; Zumla, A.; Tarkka, E.; Mero, S.; Savolainen, L.; Vaara, M.; Aittakorpi, A.; Laakso, S.; Lindfors, M.; Piiparinen, H.; et al. Accurate and rapid identification of bacterial species from positive blood cultures with a DNA-based microarray platform: An observational study. Lancet 2010, 375, 224-230. [CrossRef]

45. Clerc, O.; Prod'hom, G.; Senn, L.; Jaton, K.; Zanetti, G.; Calandra, T.; Greub, G. Matrix-assisted laser desorption ionization time-of-flight mass spectrometry and PCR-based rapid diagnosis of Staphylococcus aureus bacteraemia. Clin. Microbiol. Infect. 2014, 20, 355-360. [CrossRef]

46. Ishikawa, H.; Kutsukake, E.; Chiba, K.; Fukui, T.; Matsumoto, T. The performance of the BD geneOhm MRSA $^{\mathrm{TM}}$ assay for MRSA isolated from clinical patients in Japan, including the effects of specimen contamination and ways to improve it. J. Infect. Chemother. 2011, 17, 214-218. [CrossRef]

47. Spencer, D.H.; Sellenriek, P.; Burnham, C.A. Validation and implementation of the GeneXpert MRSA/SA blood culture assay in a pediatric setting. Am. J. Clin. Pathol. 2011, 136, 690-694. [CrossRef]

48. Stamper, P.D.; Cai, M.; Howard, T.; Speser, S.; Carroll, K.C. Clinical validation of the molecular BD geneOhm StaphSR assay for direct detection of Staphylococcus aureus and methicillin-resistant Staphylococcus aureus in positive blood cultures. J. Clin. Microbiol. 2007, 45, 2191-2196. [CrossRef]

49. Tenover, F.C.; Tickler, I.A.; Le, V.M.; Dewell, S.; Mendes, R.E.; Goering, R.V. Updating molecular diagnostics for detecting methicillin-susceptible and methicillin-resistant Staphylococcus aureus isolates in blood culture bottles. J. Clin. Microbiol. 2019, 57, e01195-Ce19. [CrossRef] 
50. Ellem, J.A.; Olma, T.; O'Sullivan, M.V. Rapid detection of methicillin-resistant Staphylococcus aureus and methicillin-susceptible $S$. aureus directly from positive blood cultures by use of the BD Max StaphSR assay. J. Clin. Microbiol. 2015, 53, 3900-3904. [CrossRef]

51. Buchan, B.W.; Allen, S.; Burnham, C.A.; McElvania TeKippe, E.; Davis, T.; Levi, M.; Mayne, D.; Pancholi, P.; Relich, R.F.; Thomson, R.; et al. Comparison of the next-generation Xpert MRSA/SA BC assay and the GeneOhm StaphSR assay to routine culture for identification of Staphylococcus aureus and methicillin-resistant S. aureus in positive-blood-culture broths. J. Clin. Microbiol. 2015, 53, 804-809. [CrossRef]

52. Blaschke, A.J.; Heyrend, C.; Byington, C.L.; Fisher, M.A.; Barker, E.; Garrone, N.F.; Thatcher, S.A.; Pavia, A.T.; Barney, T.; Alger, G.D.; et al. Rapid identification of pathogens from positive blood cultures by multiplex polymerase chain reaction using the FilmArray system. Diagn. Microbiol. Infect. Dis. 2012, 74, 349-355. [CrossRef]

53. Francois, P.; Tangomo, M.; Hibbs, J.; Bonetti, E.J.; Boehme, C.C.; Notomi, T.; Perkins, M.D.; Schrenzel, J. Robustness of a loop-mediated isothermal amplification reaction for diagnostic applications. FEMS Immunol. Med. Microbiol. 2011, 62, 41-48. [CrossRef]

54. Goldmeyer, J.; Li, H.; McCormac, M.; Cook, S.; Stratton, C.; Lemieux, B.; Kong, H.; Tang, W.; Tang, Y.W. Identification of Staphylococcus aureus and determination of methicillin resistance directly from positive blood cultures by isothermal amplification and a disposable detection device. J. Clin. Microbiol. 2008, 46, 1534-1536. [CrossRef]

55. Notomi, T.; Okayama, H.; Masubuchi, H.; Yonekawa, T.; Watanabe, K.; Amino, N.; Hase, T. Loop-mediated isothermal amplification of DNA. Nucleic Acids Res. 2000, 28, e63. [CrossRef]

56. Rödel, J.; Bohnert, J.A.; Stoll, S.; Wassill, L.; Edel, B.; Karrasch, M.; Löffler, B.; Pfister, W. Evaluation of loop-mediated isothermal amplification for the rapid identification of bacteria and resistance determinants in positive blood cultures. Eur. J. Clin. Microbiol. Infect. Dis. 2017, 36, 1033-1040. [CrossRef]

57. Marschal, M.; Bachmaier, J.; Autenrieth, I.; Oberhettinger, P.; Willmann, M.; Peter, S. Evaluation of the accelerate pheno system for fast identification and antimicrobial susceptibility testing from positive blood cultures in bloodstream infections caused by gram-negative pathogens. J. Clin. Microbiol. 2017, 55, $2116 \mathrm{e} 26$. [CrossRef]

58. Qian, Q.; Eichelberger, K.; Kirby, J.E. Rapid identification of Staphylococcus aureus in blood cultures by use of the direct tube coagulase test. J. Clin. Microbiol. 2007, 45, 2267-2269. [CrossRef]

59. Carretto, E.; Bardaro, M.; Russello, G.; Mirra, M.; Zuelli, C.; Barbarini, D. Comparison of the Staphylococcus QuickFISH BC test with the tube coagulase test performed on positive blood cultures for evaluation and application in a clinical routine setting. J. Clin. Microbiol. 2013, 51, 131-135. [CrossRef]

60. Dhiman, N.; Trienski, T.L.; DiPersio, L.P.; DiPersio, J.R. Evaluation of the BinaxNOW Staphylococcus aureus test for rapid identification of Gram-positive cocci from VersaTREK blood culture bottles. J. Clin. Microbiol. 2013, 51, 2939-2942. [CrossRef]

61. Dubourg, G.; Lamy, B.; Ruimy, R. Rapid phenotypic methods to improve the diagnosis of bacterial bloodstream infections: Meeting the challenge to reduce the time to result. Clin. Microbiol. Infect. 2018, 24, 935-943. [CrossRef]

62. Fitzgerald, C.; Stapleton, P.; Phelan, E.; Mulhare, P.; Carey, B.; Hickey, M.; Lynch, B.; Doyle, M. Rapid identification and antimicrobial susceptibility testing of positive blood cultures using MALDI-TOF MS and a modification of the standardized disc diffusion test: A pilot study. J. Clin. Pathol. 2016, 2015-203436. [CrossRef]

63. Idelevich, E.A.; Becker, K. How to accelerate antimicrobial susceptibility testing. Clin. Microbiol. Infect. 2019, 25, 1347-1355. [CrossRef] [PubMed]

64. Périllaud, C.; Pilmis, B.; Diep, J.; Péan de Ponfilly, G.; Vidal, B.; Couzigou, C.; Mizrahi, A.; Lourtet-Hascoët, J.; Le Monnier, A.; Nguyen Van, J.C. Prospective evaluation of rapid antimicrobial susceptibility testing by disk diffusion on Mueller-Hinton rapid-SIR directly on blood cultures. Diagn. Microbiol. Infect. Dis. 2019, 93, 14-21. [CrossRef] [PubMed]

65. Pilmis, B.; Thy, M.; Diep, J.; Krob, S.; Périllaud, C.; Couzigou, C.; Vidal, B.; Mizrahi, A.; Lourtet-Hascoët, J.; Le Monnier, A.; et al. Clinical impact of rapid susceptibility testing on MHR-SIR directly from blood cultures. J. Antimicrob. Chemother. 2019, 74, 3063-3068. [CrossRef] 
66. Sánchez-Carrillo, C.; Pescador, P.; Ricote, R.; Fuentes, J.; Losada, C.; Candela, A.; Cercenado, E. Evaluation of the Alfred AST ${ }^{\circledR}$ system for rapid antimicrobial susceptibility testing directly from positive blood cultures. Eur. J. Clin. Microbiol. Infect. Dis. 2019, 38, 1665-1670. [CrossRef]

67. Maxson, T.; Taylor-Howell, C.L.; Minogue, T.D. Semi-quantitative MALDI-TOF for antimicrobial susceptibility testing in Staphylococcus aureus. PLoS ONE 2017, 12, e0183899. [CrossRef] [PubMed]

68. Delport, J.A.; Mohorovic, I.; Burn, S.; McCormick, J.K.; Schaus, D.; Lannigan, R.; John, M. Rapid detection of methicillin-resistant Staphylococcus aureus bacteraemia using combined three-hour short-incubation matrix-assisted laser desorption/ionization time-of-flight MS identification and Alere Culture Colony PBP2a detection test. J. Med. Microbiol. 2016, 65, 626-631. [CrossRef]

69. Heraud, S.; Freydiere, A.M.; Doleans-Jordheim, A.; Bes, M.; Tristan, A.; Vandenesch, F.; Laurent, F.; Dauwalder, O. Direct identification of Staphylococcus aureus and determination of methicillin susceptibility from positive blood-culture bottles in a Bact/ALERT system using Binax Now S. aureus and PBP2a Tests. Ann. Lab. Med. 2015, 35, 454-457. [CrossRef]

70. Dupieux, C.; Mouton, W.; André, C.; Vandenesch, F.; Bes, M.; Tristan, A.; Laurent, F. Performance of the revised version of an immunochromatographic assay for detection of mecA- and mecC-mediated methicillin resistance in staphylococci. J. Clin. Microbiol. 2020, 58, e01346-Ce19. [CrossRef]

71. World Health Organization (WHO). Available online: https://www.who.int/news-room/detail/27-02-2017who-publishes-list-of-bacteria-for-which-new-antibiotics-are-urgently-needed (accessed on 1 August 2020).

72. Giacobbe, D.R.; Giani, T.; Bassetti, M.; Marchese, A.; Viscoli, C.; Rossolini, G.M. Rapid microbiological tests for bloodstream infections due to multidrug resistant Gram-negative bacteria: Therapeutic implications. Clin. Microbiol. Infect. 2020, 26, 713-722. [CrossRef] [PubMed]

73. Blondeau, J.M.; Idelevich, E.A. The 24-h clinical microbiology service is essential for patient management. Future Microbiol. 2018, 13, 1625-1628. [CrossRef] [PubMed]

74. Frye, A.M.; Baker, C.A.; Rustvold, D.L.; Heath, K.A.; Hunt, J.; Leggett, J.E.; Oethinger, M. Clinical impact of real-time PCR assay for rapid identification of staphylococcal bacteremia. J. Clin. Microbiol. 2012, 50, 127-133. [CrossRef] [PubMed]

75. Parta, M.; Goebel, M.; Thomas, J.; Matloobi, M.; Stager, C.; Musher, D.M. Impact of an assay that enables rapid determination of Staphylococcus species and their drug susceptibility on the treatment of patients with positive blood culture results. Infect. Control. Hosp. Epidemiol. 2010, 31, 1043-1048. [CrossRef]

76. Delerue, T.; Cordel, H.; Delerue, T.; Figoni, J.; Dziri, S.; Billard-Pomares, T.; Bouchaud, O.; Carbonnelle, E.; Zahar, J.R. Prediction of methicillin-resistant Staphylococcus aureus bloodstream infection: Do we need rapid diagnostic tests? Eur. J. Clin. Microbiol. Infect. Dis. 2019, 38, 1319-1326. [CrossRef]

77. Florio, W.; Morici, P.; Ghelardi, E.; Barnini, S.; Lupetti, A. Recent advances in the microbiological diagnosis of bloodstream infections. Crit. Rev. Microbiol. 2018, 44, 351-370. [CrossRef] [PubMed]

78. Lamy, B.; Sundqvist, M.; Idelevich, E.A. ESCMID Study Group for Bloodstream Infections, Endocarditis and Sepsis (ESGBIES). Bloodstream infections-Standard and progress in pathogen diagnostics. Clin. Microbiol. Infect. 2020, 26, 142-150.

Publisher's Note: MDPI stays neutral with regard to jurisdictional claims in published maps and institutional affiliations.

(C) 2020 by the authors. Licensee MDPI, Basel, Switzerland. This article is an open access article distributed under the terms and conditions of the Creative Commons Attribution (CC BY) license (http://creativecommons.org/licenses/by/4.0/). 